\title{
Composición, distribución y abundancia de la comunidad fitoplanctónica de la ensenada de Utría, Pacífico colombiano
}

\author{
Composition, Distribution and Abundance of the Utría Inlet Phytoplankton Community, \\ Colombian Pacific
}

\author{
Viviana Peña* y Gabriel A. Pinilla** \\ * Universidad Jorge Tadeo Lozano \\ ** Universidad Jorge Tadeo Lozano, Centro de Investigaciones Científicas y Estudios Ambientales, \\ Calle 22 3-30 P.8. Bogotá, Colombia \\ gabriel.pinilla@utadeo.edu.co
}

\begin{abstract}
Resumen.- Con el fin de caracterizar la composición, distribución y abundancia de la comunidad fitoplanctónica de la ensenada de Utría, se colectaron muestras procedentes de tres estaciones (dos costeras y una con influencia oceánica) y tres profundidades (superficie, profundidad Secchi y profundidad de compensación), tanto diurnas como nocturnas, durante los meses de julio, agosto y octubre de 1995 y febrero y julio de 1996. Se identificaron 218 especies de las cuales 137 fueron diatomeas, 73 dinoflagelados, 5 cianofíceas y 3 silicoflagelados. Dentro de esta comunidad se presentaron especies estuarinas, neríticas y oceánicas. Las principales diferencias ocurrieron entre muestreos, mientras que los cambios entre estaciones, profundidades y día-noche fueron menores. Estas variaciones probablemente fueron causadas por las entradas de aguas continentales y marinas, el régimen mareal y el lavado de playones, especialmente de las zonas de manglar.

Palabras Claves: ecología, algas marinas, fitoplancton costero.
\end{abstract}

\begin{abstract}
With the purpose of characterising the composition, distribution and abundance of the phytoplankton community of the cove of Utría, samples from three stations (two coastal and one with oceanic influence) and three depths (surface, Secchi and compensation depths), as much as diurnal and nocturnal were collected, during the months of July, August and October of 1995 and February and July of 1996. 218 species were identified, 137 were diatoms, 73 dinoflagellates, 5 cyanophytes and 3 silicoflagellates. Within this community appeared estuarine, coastal and oceanic species. Main differences occurred between samplings, while stations, depths and day-night changes were less marked. Entrances of the continental and marine waters, tide regime and washing of beaches, especially from the mangrove zones, probably caused these differences.

Keywords: ecology, marine algae, coastal phytoplankton..
\end{abstract}

\section{Introducción}

El fitoplancton del Pacífico colombiano fue estudiado en principio por Vargas-Feaucheaux et al. (1969), quienes determinaron sus características generales y las relacionaron con las variaciones oceanográficas y climatológicas atribuidas al evento "El Niño" (EN). Posteriormente, otros autores han realizado inventarios de diatomeas y dinoflagelados (Calderón 1979, Corchuelo \& Moreno 1983) y han evaluado la función de los estos grupos fitoplanctónicos y de algunas especies en particular, como indicadores de las condiciones neríticas u oceánicas de las masas de agua (Castillo \& Vidal 1982), de enriquecimiento con nutrientes (Castillo 1982, 1984) y de aumento en la temperatura debido al EN (Constain \& Delgado 1985). Delgado \& Leyton (1985) cuantificaron el fitoplancton mediante mediciones de clorofila a y cartografiaron las áreas más productivas del Pacífico colombiano durante el EN más riguroso (1982). Igualmente, se ha estudiado la distribución de las especies más frecuentes de diatomeas (Montagut \& Castillo 1989) y dinoflagelados (Oviedo 1989) en relación con la temperatura y salinidad del agua. Vizcaíno (1992) y Mora (1993) investigaron, respectivamente, la relación de los dinoflagelados con el EN de 1992 y como indicador de zonas de surgencia. Últimamente, Sánchez (1996) caracterizó espacialmente el fitoplancton nerítico del Pacífico colombiano y destacó la abundancia de organismos como una variable que mostró tendencia a incrementarse conforme decrece la latitud. No obstante, la mayoría de estos estudios se han realizado en aguas oceánicas (donde la profundidad es mayor a $200 \mathrm{~m}$ ) y hasta la fecha existen muy pocos en aguas costeras. Específicamente para el área de la ensenada de Utría, la cual es una zona de reserva importante por estar dentro de la región megadiversa del Chocó biogeográfico colombiano (Vieira 1994), no se han hecho trabajos sobre el fitoplancton, por lo que este estudio 
complementa la información de microalgas planctónicas para Colombia y para el Pacífico Suroriental en general. La investigación tuvo como objetivo identificar las especies fitoplanctónicas de la ensenada de Utría y estudiar sus variaciones temporales (durante un año), espaciales (de acuerdo con la presencia de algunos ecosistemas dentro de la ensenada como manglar y coral) y verticales en la columna de agua (a tres profundidades); también se evaluó la comunidad en el día y en la noche para determinar los efectos del ciclo luz oscuridad sobre la composición y abundancia de las algas.

\section{Materiales y Métodos}

Area de Estudio. La ensenada de Utría se localiza a $6^{\circ} 4^{\prime}$ Latitud Norte y $77^{\circ} 25^{\prime}$ Longitud Oeste y forma parte del Parque Nacional Natural Utría (P.N.N.U.), el cual se encuentra en una las áreas de mayor diversidad biológica del mundo (Vieira 1994). Se orienta de sur a norte y está rodeada por montañas de poca elevación; tiene una longitud aproximada de $4 \mathrm{~km}$ y un ancho, en su punto medio, de $800 \mathrm{~m}$ en marea baja (Vieira 1994) (Fig. 1). Los cordones montañosos aledaños presentan

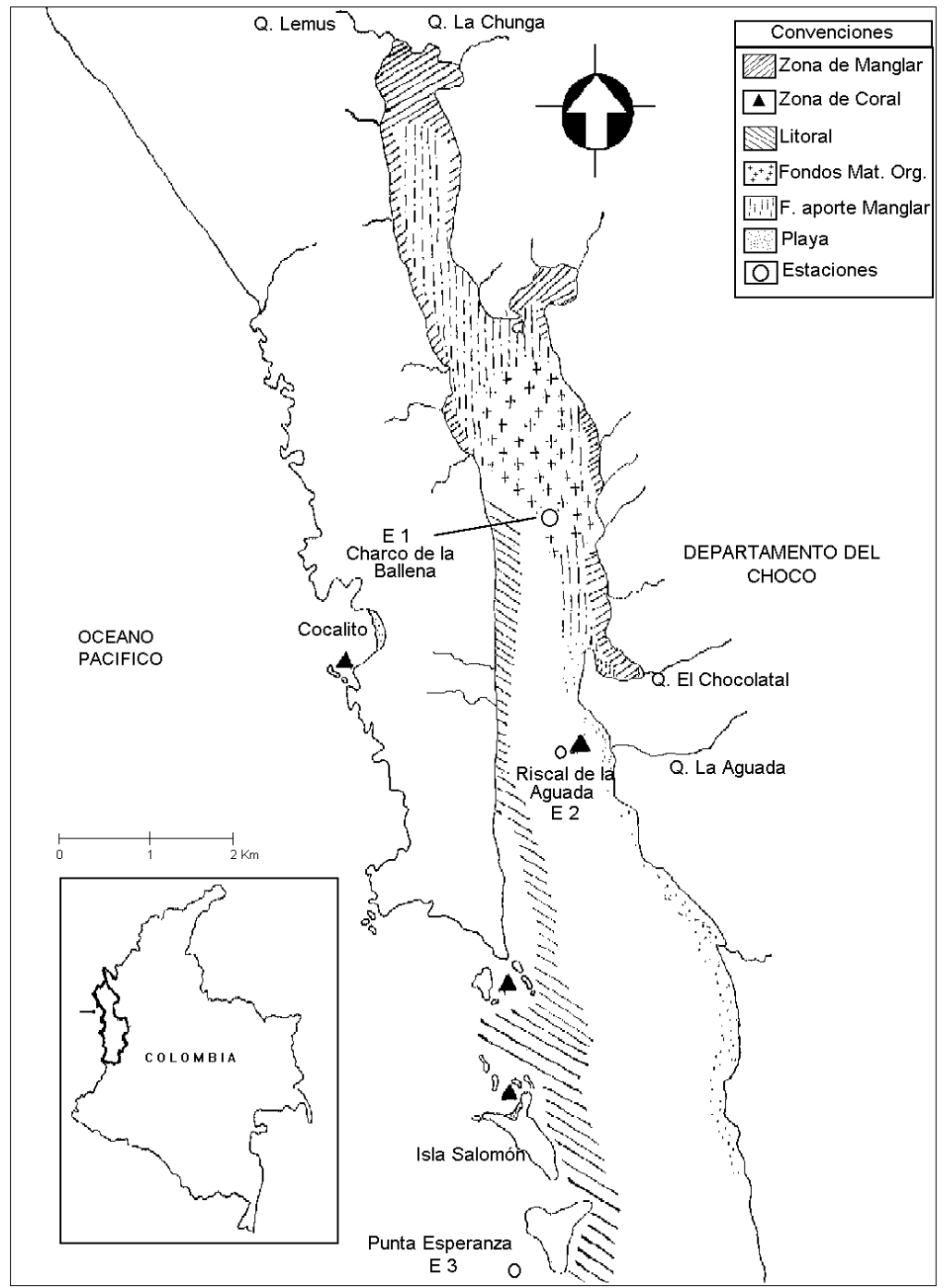

Figura 1

Ubicación de las estaciones de muestreo en la ensenada de Utría (Modificado de Vieira 1994) Location of the sampling stations in the cove of Utría (Modified from Vieira 1994) 
selva húmeda tropical; las zonas norte y oriental de la ensenada están cubiertas por angostas franjas de manglar (Arboleda 1988, Prahl et al. 1990). La pluviosidad anual se acerca a los $7000 \mathrm{~mm}$ y la humedad relativa llega al $99 \%$ en los meses lluviosos (Vieira 1994). Las lluvias son permanentes todo el año con una ligera disminución entre diciembre y abril, época denominada localmente "verano", y con las mayores precipitaciones en el "invierno", que corresponde a los meses de agosto, septiembre octubre y noviembre; mayo a julio constituyen el "veranillo" y se caracterizan por la alternancia de días nublados y soleados sin un patrón definido. Estas épocas dependen del desplazamiento del Frente de Convergencia Intertropical (FCI) (Díaz 1993, Vieira 1994). Las mareas, que son de tipo semidiurno con un rango que puede sobrepasar los $4 \mathrm{~m}$ (régimen mesomareal alto o macromareal), afectan las corrientes internas de la ensenada y provocan la entrada y salida de grandes volúmenes de agua. Estas corrientes pueden alcanzar grandes velocidades (cercanas a $2 \mathrm{~m} \mathrm{~s}^{-1}$ ) en épocas de mareas máximas, lo que ocasiona la deposición o remoción de sedimentos en algunas zonas de la bahía (Prahl et al. 1990).

Sitios y fechas de muestreo. Los sitios se seleccionaron considerando la presencia de otras comunidades, especialmente de manglar y coral, las cuales están a diferentes distancias de la costa. De acuerdo con esto, se determinaron tres estaciones de muestreo: Charco de la Ballena (E1), nerítica, localizada en la confluencia de las cuatro zonas de manglar de la ensenada, con profundidades entre 15 y $18 \mathrm{~m}$; Riscal de la Aguada (E2), nerítica, situada sobre un parche coralino, cuya profundidad media es de $15 \mathrm{~m}$ y Punta Esperanza (E3), nerítica con influencia de aguas abiertas, localizada en el extremo sur de la ensenada, de carácter rocoso y con 60 a $80 \mathrm{~m}$ de profundidad (Fig. 1). Los muestreos se efectuaron en periodos de una semana en los meses de julio, agosto y octubre de 1995 y febrero y julio de 1996.

Variables físicas y químicas. En cada estación y profundidad se obtuvieron datos de temperatura, salinidad, oxígeno disuelto (OD) y transparencia, de acuerdo con las recomendaciones de APHA (1992).

Muestras cualitativas. La recolección de los organismos fitoplanctónicos se realizó con una red cónica simple con tamaño de poro de $52 \mu$, mediante arrastres superficiales circulares (velocidad promedio de 2 nudos durante 4 minutos, Balech 1977); las muestras se preservaron en frascos plásticos con solución transeau, de acuerdo con Pinilla (1995). Para la identificación taxonómica de los organismos se utilizaron los trabajos y las claves taxonómicas de Kofoid \& Skossberg (1928), Cupp (1943), Davis
(1964), Steidinger (1964), Wahlquist (1964), Avaria (1965), Dodge (1975), Taylor (1987), Vidal \& Carbonell (1977), Pesantes (1978), Mora (1993) y Corchuelo \& Moreno (1983), entre otros.

Muestras cuantitativas. Con una botella alpha horizontal de $3 \mathrm{l}$ de capacidad se tomaron muestras en superficie (0,3 m), en la profundidad del disco Secchi y en la profundidad de compensación (profundidad del disco Secchi multiplicada por 3, Odum 1986) entre las 10:00 y las 12:00; en la noche se tomaron las mismas muestras entre las 18:00 y las 20:00. La preservación se hizo con lugol concentrado y la cuantificación de los organismos se realizó con el método de concentración por sedimentación en cámaras Utermöhl (Lund et al. 1958). Estas cámaras de sedimentación se dejaron decantar dos horas por cada ml empleado; las algas sedimentadas se contaron en un microscopio invertido (aumento 10X) y la abundancia se calculó teniendo en cuenta el volumen sedimentado y el número de campos visuales contados. Generalmente se contaron entre 30 y 45 campos por cámara de sedimentación, ya que según Ramírez (1992) este número de campos permite aproximarse al $90 \%$ de los organismos presentes en la superficie de conteo.

Análisis numérico. Se hicieron análisis de varianza para examinar las diferencias significativas de las características fisicoquímicas del agua entre los muestreos y se empleó el test de Kruskal-Wallis para determinar los muestreos que fueron diferentes (Ramírez 1999). Para establecer la similitud entre las estaciones se realizaron análisis de clasificación mediante el índice de Bray-Curtis y la estrategia de agrupamiento por promedio simple (Digby \& Kempton 1987), a partir de los datos estandarizados de las variables fisicoquímicas y de las abundancias fitoplanctónicas. Se determinaron los índices de diversidad de Shannon, de dominancia de Simpson y de proporcionalidad (diversidad/diversidad máxima) como herramientas para interpretar la relación entre el número de especies y su abundancia (Ludwing \& Reynolds 1988, Ramírez 1999).

\section{Resultados y Discusión}

Ambiente físico y químico. A pesar de la presencia del manglar, las aguas de la ensenada de Utría presentan en general transparencias altas $(4,5$ a $14 \mathrm{~m}$, tabla 1) comparadas con otras zonas del Pacífico colombiano. Sánchez (1996) encontró que entre 1 y 10 millas de distancia a la costa la transparencia fluctúa entre 0,5 y $10,5 \mathrm{~m}$. En la ensenada la profundidad Secchi fue muy variable entre los muestreos en todas las estaciones. Sin embargo, fue notoria la menor transparencia en la estación 1 como consecuencia de las aguas más turbias 
procedentes de las áreas de manglar (tabla 1). La estación 3 dejó ver claramente la menor influencia de procesos causantes de turbidez por estar más alejada de la costa, especialmente en julio de 1995 y febrero de 1996, sin ser completamente ajena al material en suspensión proveniente de escorrentías y de materia orgánica producida en el sistema estuarino; además, fue la estación con mayores fluctuaciones de las corrientes externas. La estación 2 tuvo un comportamiento intermedio que se parece más a las condiciones abiertas de la ensenada, lo cual muestra la fuerte influencia de las aguas que entran a Utría.
La temperatura promedio diurno del agua en los cinco muestreos y para todas las estaciones y profundidades fue de $27,4^{\circ} \mathrm{C}$. En superficie osciló entre 24 y 29,5 ${ }^{\circ} \mathrm{C}$, en la profundidad Secchi entre 27 y 28,2 ${ }^{\circ} \mathrm{C}$ y en la profundidad de compensación entre 21,5 y 28,2 ${ }^{\circ} \mathrm{C}$ (tabla 1). Los rangos anteriores son bastante amplios y no permiten definir una estratificación térmica por profundidad, lo cual es normal en aguas estuarinas (Prahl et al. 1990). Sin embargo, en julio de 1996 se presentó una marcada variación entre la superficie y el fondo en las estaciones 2 y 3 (tabla 1), lo que podría indicar la formación de una termoclina o la presencia de masas profundas de agua fría, provenientes del sur.

Tabla 1

Valores diurnos de profundidad Secchi, profundidad de compensación, temperatura, salinidad, oxígeno disuelto y porcentaje de saturación de oxígeno en las diferentes estaciones y profundidades de la ensenada de Utría (E: Estación)

Diurnal values of transparency, compensation depth, temperature, salinity, dissolved oxygen and oxygen saturation percentage in the different stations and depths of the cove of Utría (E: Station)

\begin{tabular}{|c|c|c|c|c|c|c|c|c|c|c|c|c|c|c|c|}
\hline \multirow{3}{*}{$\begin{array}{l}\text { Profundidad } \\
\text { de Muestreo }\end{array}$} & \multicolumn{3}{|c|}{ Julio de 1995} & \multicolumn{3}{|c|}{ Agosto de 1995} & \multicolumn{3}{|c|}{ Octubre de 1995} & \multicolumn{3}{|c|}{ Febrero de 1996} & \multicolumn{3}{|c|}{ Julio de 1996} \\
\hline & E 1 & E 2 & E 3 & E 1 & E 2 & E 3 & E 1 & E 2 & E 3 & E 1 & E 2 & E 3 & E 1 & E 2 & E 3 \\
\hline & \multicolumn{15}{|c|}{ Transparencia y Profundidad de Compensación (m) } \\
\hline Prof. Secchi & 7 & 11 & 14 & 5 & 9 & 6 & 7 & 9 & 10 & 4,5 & 6 & 11 & 7 & 10 & 10 \\
\hline \multirow{2}{*}{$\begin{array}{l}\text { Prof. De } \\
\text { Comp. }\end{array}$} & 21 & 33 & 42 & 15 & 27 & 18 & 21 & 27 & 30 & 13,5 & 18 & 33 & 21 & 30 & 30 \\
\hline & \multicolumn{15}{|c|}{ Temperatura $\left({ }^{0} \mathrm{C}\right)$} \\
\hline Superficie & 28,2 & 28,2 & 28 & 28,2 & 28 & 28 & 29 & 29 & 24 & 28,2 & 28,5 & 28,2 & 26,7 & 29,5 & 28,2 \\
\hline Prof. Secchi & 28,2 & 28,2 & 27,7 & 28 & 28 & 28,2 & 28,2 & 28,2 & 27,5 & 28 & 27 & 27,5 & 28 & 28,2 & 28 \\
\hline $\begin{array}{l}\text { Prof. De } \\
\text { Comp. }\end{array}$ & 28 & 28 & 28 & 27,5 & 27,5 & 28,2 & 28 & 27,5 & 25,5 & 26,7 & 25 & 25,7 & 27,7 & 22,5 & 21,5 \\
\hline
\end{tabular}

Salinidad (UPS)

\begin{tabular}{|c|c|c|c|c|c|c|c|c|c|c|c|c|c|c|c|}
\hline Superficie & 25,5 & 31,5 & 31,5 & 27 & 28,5 & 23,5 & 20 & 21 & 21,5 & 21,5 & 22,5 & 20 & 23 & 19 & 19,5 \\
\hline Prof. Secchi & 25,5 & 31 & 30 & 27 & 29 & 26,5 & 24 & 26 & 26 & 26,5 & 20 & 22 & 22 & 24,5 & 27,5 \\
\hline $\begin{array}{l}\text { Prof. De } \\
\text { Comp. }\end{array}$ & 26,5 & 32,5 & 29 & 28,5 & 30,5 & 28,5 & 27 & 25,5 & 25,5 & 28,5 & 21 & 22 & 23 & 28 & 31 \\
\hline
\end{tabular}

Oxígeno Disuelto (mg l $\left.{ }^{-1}\right)$

\begin{tabular}{lccccccccccccccc}
\hline Superficie & 7,1 & 7 & 6,6 & 7,3 & 6,6 & 6,9 & 7,9 & 8,2 & 7,9 & 7,5 & 7,4 & 7,5 & 7,4 & 7,3 & 7,8 \\
Prof. Secchi & 6,8 & 7 & 7 & 7,1 & 6,3 & 7,5 & - & - & - & 6,2 & 6,3 & 7,6 & 6,7 & 6,7 & 6,9 \\
$\begin{array}{l}\text { Prof. De } \\
\text { Comp. }\end{array}$ & 7,1 & 6,6 & 6,2 & 7,2 & 5,9 & 7,3 & - & - & - & 6,3 & 6,1 & 7,2 & 6,7 & 5,6 & 5,9 \\
\end{tabular}

Saturación de Oxígeno (\%)

\begin{tabular}{lccccccccccccccc}
\hline Superficie & 92,6 & 90,6 & 85,1 & 95,2 & 85,1 & 89,6 & 106 & 112,9 & 106 & 101 & 103 & 101 & 94,1 & 103 & 111,2 \\
Prof. Secchi & 88,7 & 90,6 & 89,9 & 91,5 & 81,2 & 97,7 & - & - & - & 82 & 75 & 99,1 & 81,9 & 83,8 & 99,4 \\
Prof. de Comp. & 91,6 & 85,7 & 79,9 & 92,3 & 70 & 95 & - & - & - & 75,7 & 71,5 & 101 & 81,2 & 73 & 80,6 \\
\hline
\end{tabular}


El valor promedio diurno de salinidad fue de 25,39 UPS, para todas las estaciones, profundidades y muestreos. Los valores superficiales oscilaron entre 19 y 31,5 UPS, en la profundidad Secchi estuvo entre 20 y 31UPS y en la de compensación fluctuó entre 21 y 32,5 UPS (tabla 1). Estos valores son normales para las aguas de la ensenada, según trabajos realizados en el Pacífico colombiano que registran salinidades entre 13 y 35 UPS (Corchuelo \& Moreno 1983, Delgado \& Leyton 1985, Sánchez 1996). El análisis de varianza mostró diferencias significativas de la salinidad superficial entre los muestreos ( $\mathrm{F}=9,5 \mathrm{P}=0,0019)$ dadas, según el test de Kruskal-Wallis, por mayores valores en los meses de julio y agosto de 1995. En general, las mayores salinidades de las tres profundidades se presentaron en el muestreo de julio de 1995, en el cual el promedio fue de 29,2 UPS. El muestreo que presentó los menores valores en las tres profundidades fue el de febrero de 1996 (promedio 21,7 UPS). Estas variaciones en la salinidad en la ensenada parecen estar determinadas por las entradas de agua dulce continental provenientes de quebradas como La Lemus, La Chunga y La Aguada, entre otras, y por las lluvias locales y la escorrentía de las zonas de manglar y selváticas, especialmente en julio y agosto. El aumento en la salinidad depende de los flujos de agua marina, ya sean vaciantes o de llenado (según el comportamiento mareal). En los muestreos diurnos las tres profundidades de la estación 1 presentaron los menores promedios de salinidad (23,1, 24,7 y 26 UPS, respectivamente), seguramente porque están menos afectadas por la entrada de aguas oceánicas, a la vez que poseen mayores aportes continentales procedentes de las quebradas. En todos los muestreos las tres estaciones registraron los mayores valores de salinidad en la profundidad de compensación. Esto se debe posiblemente a la reducida influencia de las lluvias en las aguas profundas; el efecto de cuña (Prahl et al. 1990), según el cual el agua salobre penetra por el fondo debido a su mayor densidad, es otra posible explicación a la mayor salinidad en las aguas de fondo.

Los meses de julio y agosto de 1995 tuvieron estadísticamente menos oxígeno disuelto en superficie, de acuerdo con el análisis de varianza realizado $(\mathrm{F}=10,54 \mathrm{P}=0,0013)$. Sin embargo, los valores de oxígeno fueron en general altos para todos los muestreos (tabla 1); el promedio para todas las estaciones y profundidades fue de 6,93 $\mathrm{mg} \mathrm{l}^{-1}$. Estas concentraciones son mayores a las encontradas por Delgado \& Leyton (1985) y Sánchez (1996) (3,5 y $5 \quad \mathrm{mg}^{-1}$, respectivamente) en las aguas del Pacífico colombiano. Los porcentajes de saturación estuvieron en su mayoría entre 87 y 112,2 \% (tabla 1), es decir, en niveles que van desde ligeramente subsaturados hasta ligeramente saturados. Un comportamiento similar se presentó en la laguna costera de Cocoliso en el Caribe colombiano
(Gualteros et al.1992), aunque las variaciones en los porcentajes de saturación fueron más severas, ya que fluctuaron entre el 43 y 149\% durante el día.

Composición del fitoplancton. El análisis, tanto de las muestras cualitativas como de las cuantitativas de los cinco muestreos realizados, permitió identificar 218 especies (agrupadas en 64 géneros) de las cuales 137 fueron diatomeas, 73 dinoflagelados, 5 cianofíceas y 3 silicoflagelados (tabla 2). Según las características ecológicas de los fitopláncteres, la ensenada de Utría presenta una comunidad "mezclada" en la que coexisten especies de tipo nerítico, oceánico y estuarino. Las especies más frecuentes durante todos los muestreos fueron Chaetoceros diversum y Coscinodiscus sp.3 (92\%), Rhizosolenia calcar-avis y Ceratium fusus (91\%), Ch. lorenzianus (90\%), Pyrocystis fusiformis (88\%) y Cerataulina pelagica (77\%) (tabla 3). Su alta frecuencia posiblemente se debió a que son especies cosmopolitas de hábitats neríticos, comunes en los mares tropicales y que se desarrollan en aguas oligotróficas (Sournia 1967, Davis 1964). Saunders (1968) describe a C. pelagica como una especie que habita las desembocaduras de los ríos, bahías, estuarios y lagunas costeras; sus poblaciones aumentan cuando en el medio se presentan los nutrientes necesarios para su desarrollo y pueden ser dominantes cuando se incrementan las concentraciones de los mismos, ya que la presencia de nitrógeno, fósforo, hierro y sílice estimulan su crecimiento. En los trabajos de Corchuelo \& Moreno (1983) y Sánchez (1996), estos taxones fueron escasos, excepto $C$. fusus, lo cual podría señalar que esta especie se desarrolla tanto en ambientes estuarinos cálidos como en los oceánicos fríos. Davis (1964) considera este organismo como dominante o subdominante en estuarios, sin que llegue a ser estrictamente estuarino.

Tabla 2

Especies fitotoplanctónicas de la ensenada de Utria Phytoplankton species of the cove of Utria

\author{
CLASE: Diatomophyceae \\ Melosira moniliformis (Müller) Agardh \\ Coscinodiscus spp. (3 especies) \\ Actinocyclos sp. 1 \\ Skeletonema costatum (Gréville) Cleve 1873 \\ Skeletonema tropicum Cleve, 1900 \\ Planktoniella sol (Wallich) Schutt, 1893 \\ Asteromphalus hookeri Ehrenberg, 1844 \\ Asteromphalus spp. (2 especies) \\ Actinoptychus senarius Ehrenberg 1843 \\ Biddulphia mobiliensis (Bailey) Grunow, 1880
}


(Cont. Tabla 2)

Biddulphia obtusa (Kützing) Ralfs in Pritchard, 1861

Biddulphia regia (Schultze) Ostenfeld, 1908

Biddulphia membranacea Cleve, 1878

Biddulphia pulchella Gray, 1821

Hemialus hauckii Grunow, 1880

Hemialus membranaceus Cleve, 1873

Hemialus sinensis Gréville, 1865

Eucampia sp. 1

Climacodium biconcavum Cleve

Climacodium frauenfeldianum Grunow, 1867

Triceratium antediluvianum (Ehrenberg) Grunow

Isthmia enervis Ehrenberg

Ditylum brightwelli (West) Grunow 1883

Cerataulina pelagica (Cleve) Hendey 1937

Lithodesmium undulatum Ehrenberg 1841

Terpsinoe musica Ehrenberg

Chaetoceros affinis Lauder, 1864

Chaetoceros brevis Schütt, 1895

Chaetoceros coarctatus Lauder, 1864

Chaetoceros compressus Lauder, 1864

Chaetoceros denticulatus Lauder

Chaetoceros didymus Ehrenberg, 1845

Chaetoceros diversus Cleve, 1873

Chaetoceros laciniosus Shütt, 1895

Chaetoceros lorenzianus Grunow, 1867

Chaetoceros messanensis Castracane, 1875

Chaetoceros peruvianus Brightwell, 1856

Chaetoceros spp (8 especies)

Bacteriastrum cf. hyalinum Lauder, 1864

Bacteriastrum cf. delicatulum Cleve, 1897

Corethron criophilum Castracane, 1886

Proboscia alata Brightwell, 1855

Rhisozolenia calcar-avis Schultze, 1858

Rhisozolenia hebetata Bailey (Hensen) Gran, 1904

Rhisozolenia imbricata Brightwell, 1858

Rhisozolenia setigera Brightwell, 1858

Guinardia striata (Stolterfoth) Hasle, 1996

Guinardia flaccida (Castracane) Peragallo, 1892

Leptocylindrus sp. 1

Asterionella sp. 1

Plagiogramma sp. 1

Synedra undulata Bailey

Synedra spp. (2 especies)

Neodelphineis pelagica Tacano, 1982

Thalassionema nitzschioides (Grunow) Mereschkowsky, 1902

Thalassionema sp. 1

Licmophora ehrenbergii (Kützing) Grunow, 1844

Licmophora hyalina

Licmophora sp. 1

Climacosphenia moniligera Ehrenberg

Grammatophora marina (Lyngbye) Kützing

Rhabdonema sp. 1

Podocystis sp. 1

Achnanthes sp. 1
(Cont. Tabla 2)

Navicula lyra Ehrenberg

Navicula spp. (24 especies)

Trachyneis spp. (2 especies)

Diploneis spp. (2 especies)

Stauroneis sp. 1

Gyrosigma balticum (Ehrenberg) Cleve

Pleurosigma spp. (4 especies)

Donkinia recta (Cleve) Cox

Amphiprora alata (Ehrenberg) Kütz

Amphiprora sp. 1

Amphora spp. (11 especies)

Thalassiophysa sp. 1

Nitzschia closterium (Ehrenberg) W. Schmith

Nitzschia longissima (Brébisson) Ralfs 1861

Pseudo-nitzschia pungens (Grunow ex Cleve) Hasle 1993

Nitzschia spp. (4 especies)

Surirella fastuosa (Ehrenberg) Kützing, 1844

Surirella gemma (Ehrenberg) Kützing

Surirella sp. 1

Diatomeas pennadas sin identificar (3)

\section{CLASE: Dinophyceae}

Phalachroma (Dinophysis) doryphorum Stein, 1883

Phalachroma (Dinophysis) porodictyum Stein, 1883

Phalachroma (Dinophysis) rapa Jörgensen, 1923

Dinophysis caudata Saville \& Kent, 1881

Dinophysis hastata Stein, 1883

Dinophysis ovum Schütt, 1895

Dinophysis spp. (2 especies)

Ornithocercus thumii (Schmidth) Kofoid \& Skogsberg

Ornithocercus magnificus Stein, 1883

Ornithocercus steinii Schütt, 1900

Histioneis sp. 1

Gyrodinium splendens Lebour, 1925

Gyrodinium sp. 1

Ceratium breve (Ostenfeld \& Scmidt) Schröder, 1906

Ceratium carriense Gourret, 1883

Ceratium candelabrum (Ehrenberg) Stein, 1883

Ceratium contortum (Gourret) Cleve, 1900

Ceratium contrarium (Gourret) Pavillard, 1905

Ceratium deflexum (Kofoid) Jörgensen, 1911

Ceratium extensum (Gourret) Cleve, 1901

Ceratium falcatiforme Jörgensen, 1920

Ceratium falcatum Jörgensen, 1920

Ceratium furca (Ehrenberg) Claparede \& Lachmann, 1859

Ceratium fusus (Ehrenberg) Dujardin, 1841

Ceratium inflatum (Kofoid) Jörgensen, 1911

Ceratium kofoidii Jörgensen, 1899

Ceratium longirostrum Gourret, 1883

Ceratium macroceros (Ehrenberg) Vanhöffen, 1897

Ceratium massiliense (Gourret) Jörgensen, 1911

Ceratium porrectum (Karsten) Jörgensen, 1911

Ceratium strictum (Okamura \& Nishikawa) Kofoid, 1907

Ceratium trichoceros (Ehrenberg) Kofoid, 1908 
(Cont. Tabla 2)

Ceratium tripos (O. F Müler) Nitzsch, 1817

Ceratium vultur Cleve, 1900

Ceratocorys horrida Stein, 1883

Ceratocorys armata (Schütt) Kofoid, 1910

Gonyaulax diegensis Kofoid, 1911

Gonyaulax fragilis (Schütt, 1895) Kofoid

Gonyaulax polygramma Stein, 1883

Gonyaulax turbinei Murray \& Whitting, 1899

Spiraulax sp. 1

Heterocapsa sp. 1

Oxytoxum scolopax Stein, 1883

Protoperidinium abei (Paulsen) Balech, 1974

Protoperidinium depressum (Bailey) Balech, 1974

Protoperidinium divergens (Ehrenberg) Balech, 1974

Protoperidinium elegans (Cleve) Balech, 1974

Protoperidinium grande (Kofoid) Balech, 1974

Protoperidinium pentagonum (Gran) Balech, 1974

Protoperidinium steinii (Jörgensen) Balech, 1974

Protoperidinium spp (11 especies)

Diplopsalis lenticula Bergh, 1881

Podolampas bipes Stein, 1883

Podolampas palmipes Stein, 1883
(Cont. Tabla 2)

Podolampas spinifera Okamura, 1912

Pyrophacus horologicum Stein, 1883

Prorocentrum micans Ehrenberg, 1833

Prorocentrum lenticulatum Matzenauer, 1933

Prorocentrum gracile Schütt, 1895

Pyrocystis fusiformis (Wyville Thompson) Murray in Schiller, 1937

Pyrocystis robusta Kofoid, 1907

Kofoidinium velleloides Pavillard

Cistodinoflagelado sin identificar (1)

CLASE: Dictyochophyceae

Dictyocha fibula Ehrenberg

Dictyocha octonaria Ehrenberg

Hermesinum adriaticum Zacharias

CLASE: Cyanophyceae

Oscillatoria spp. (3 especies)

Spirulina sp. 1

Tabla 3

Sumatorias, promedios y frecuencias de aparición de algunas de las especies fitoplanctónicas más importantes de la ensenada de Utría

Sums, averages and frequencies of appearance of some of the more important phytoplanktonic species of the cove of Utría

\begin{tabular}{|c|c|c|c|}
\hline Especie & $\begin{array}{c}\text { Sumatoria } \\
\text { en todas las muestras } \\
\left(\text { células } \mathbf{~}^{-1}\right) \\
\end{array}$ & $\begin{array}{c}\text { Promedio } \\
\text { en las muestras } \\
\left(\text { células } \mathbf{l}^{-1}\right) \\
\end{array}$ & $\begin{array}{c}\text { Frecuencia } \\
\text { de aparición en las muestras } \\
(\%) \\
\end{array}$ \\
\hline Amphora sp. 2 & 31,4 & 0,3 & 47,8 \\
\hline Bacteriastrum delicatulum & 76 & 0,8 & 51,1 \\
\hline Cerataulina pelagica & 455,1 & 5,1 & 77,8 \\
\hline Ceratium breve & 44,1 & 0,5 & 50 \\
\hline Ceratium furca & 127,6 & 1,4 & 85,6 \\
\hline Ceratium fusus & 142,3 & 1,6 & 91,1 \\
\hline Corethron criophilum & 33 & 0,4 & 50 \\
\hline Coscinodiscus sp. 1 & 107,1 & 1,2 & 70 \\
\hline Coscinodiscus sp. 3 & 113,8 & 1,3 & 92,2 \\
\hline Chaetoceros diversus & 568,5 & 6,3 & 92,2 \\
\hline Chaetoceros didymus & 325,1 & 3,7 & 84,4 \\
\hline Chaetoceros lorenzianus & 376,6 & 4,2 & 90 \\
\hline Chaetoceros peruvianus & 145,7 & 1,6 & 81,1 \\
\hline Guinardia flaccida & 85 & 0,9 & 47,8 \\
\hline Pyrocystis fusiformis & 79 & 0,9 & 88,9 \\
\hline Rhizosolenia calcar-avis & 314,4 & 3,5 & 91,1 \\
\hline
\end{tabular}


Especies como Skeletonema costatum, Guinardia flaccida, Bacteriastrum delicatulum, Ceratium breve, Corethron criophilum y Amphora sp. 2 tuvieron frecuencias entre 44 y 50\% (tabla 3). Las especies $S$. costatum y $G$. flaccida se catalogan como adiafóricas, es decir, presentes tanto en zonas neríticas como oceánicas (Oviedo 1989). C. breve y C. criophilum son oceánicas y de aguas cálidas (Pesantes 1978, Avaria 1965), por lo cual su presencia en la ensenada de Utría puede indicar, por una parte, condiciones térmicas favorables para su desarrollo, y por otra, que la estrechez de la plataforma continental en este sector de la costa permite a dichas especies estar más cerca del continente; dicho efecto puede incrementarse por los vientos que soplan desde el mar abierto hacia la ensenada. En trabajos como los de Castillo (1984), Constain \& Delgado (1985) y Escobar et al. (1993), C. breve se registró como una de las especies más abundantes y frecuentes e indicadora de aguas cálidas durante los EN. Su abundancia intermedia (50\%) en las aguas de Utría no señala necesariamente este fenómeno, ya que en condiciones normales presenta este tipo de frecuencia (Carbonell 1982, Sánchez 1996). S. costatum fue la única especie de Utría que Calderón (1979), Corchuelo \& Moreno (1983) y Sánchez (1996) registraron también como frecuente, tal vez favorecida por las bajas salinidades y los aportes de agua continental. En la región manglárica de Bengala (India) también se registró a $S$. costatum como una especie frecuente y con altas abundancias (Santra et al. 1991). Las especies Phalachroma (Dinophysis) rapa, Pseudonitzschia pungens, Ceratium vultur y Protoperidinium elegans presentaron frecuencias mínimas del 1,1\%. Estas especies raras son propias de condiciones tropicales oceánicas, las cuales pueden ocurrir en Utría, pero no en forma permanente. Su presencia en la ensenada pudo darse porque estas especies son euritermas y eurihalinas (Corchuelo \& Moreno 1983). Los silicoflagelados Dictyocha fibula y D. octonaria, presentaron abundancias relativamente bajas y apariciones ocasionales. La escasez de silicoflagelados se debe a que estas microalgas son más frecuentes en ambientes oceánicos; en las costas peruanas, por ejemplo, Antonietti (1988) halló 103 células por $\mathrm{ml}^{-1}$ de D. fibula. Sin embargo su aparición, no sólo en la ensenada de Utría sino en el Pacífico colombiano en general (Calderón 1979, Sánchez 1996), puede estar favorecida por la interacción de variables como la salinidad, el oxigeno disuelto, las corrientes marinas y especialmente la temperatura, debido a que esta especie prefiere aguas cálidas (Avaria 1965).

Variaciones temporales de la abundancia celular. Las mayores densidades celulares totales se registraron en el muestreo de febrero de 1996, en el cual la estación 2 presentó 1471 células $\mathrm{ml}^{-1}$. Por el contrario, en el muestreo de julio de 1996 se observaron las menores abundancias totales, con valores de 79 células $\mathrm{ml}^{-1}$ en la estación 3 (Fig. 2). Las abundancias máximas registradas en el presente estudio se pueden considerar bajas si se comparan con trabajos como el de Sánchez (1996), quien determinó concentraciones hasta de 5600 células $\mathrm{ml}^{-1}$, y el de Mosquera (1992), según el cual se presentan abundancias que llegan a 214373 células $\mathrm{ml}^{-1}$ en las aguas eutróficas de la ensenada de Tumaco. Las abundancias fitoplanctónicas en Utría sugieren un carácter oligotrófico en sus aguas, en correspondencia con la alta precipitación en la zona de la ensenada. En cuanto a las diferencias entre el día y la noche se observó que las diatomeas presentaron siempre el mayor porcentaje, tanto en los muestreos diurnos como en los nocturnos (Fig. 3). Estos resultados muestran que la distribución circadiana de las diatomeas, que no poseen capacidad de movimiento como los dinoflagelados, depende básicamente de la turbulencia y de la mezcla de la columna de agua, por lo que se encuentran en abundancias similares en el día y en la noche. Los demás grupos fueron menos abundantes; sin embargo, en algunos muestreos los dinoflagelados presentaron un mayor porcentaje en las horas nocturnas debido posiblemente a los movimientos nictimerales que presentan estos organismos (Balech 1977). Taylor (1987) encontró que los dinoflagelados se concentran alrededor de la picnoclina, quizás porque allí se encuentra el alimento que requieren; cuando en la noche la picnoclina sube por pérdida de calor en superficie, los dinoflagelados suben con ella y se localizan más cerca a la superficie; este fenómeno, aunque no se midió en este trabajo, podría ayudar a explicar el aumento de dinoflagelados en la noche. Las cianofíceas representadas principalmente por especies de Oscillatoria y Spirulina, superaron a los dinoflagelados tanto en el día como en la noche en los muestreos de julio, agosto y octubre de 1995, lo que insinúa carencia de nitrógeno en las aguas de Utría, ya que algunas especies de este grupo son capaces de fijar nitrógeno libre, entre ellas las del género Oscillatoria (Paerl 1988, Reynolds 1997); sin embargo, esta tesis deberá contrastarse en el futuro mediante la medición de las diferentes fracciones de nitrógeno. Por otra parte, en la sucesión fitoplanctónica las cianofíceas prosperan cuando el periodo de lluvias alcanza su mayor intensidad (Vidal com. per. ${ }^{1}$ ), lo cual explicaría su abundancia en los muestreos indicados.

Variaciones en la columna de agua. En porcentaje, las diatomeas fueron siempre las más abundantes en las tres profundidades consideradas (Fig. 4). Su dominancia es independiente de la profundidad debido a que están

\footnotetext{
${ }^{1}$ Alfonso Vidal, Biólogo Marino, Instituto de Investigaciones Marinas INVEMAR, Santa Marta, Colombia.
} 


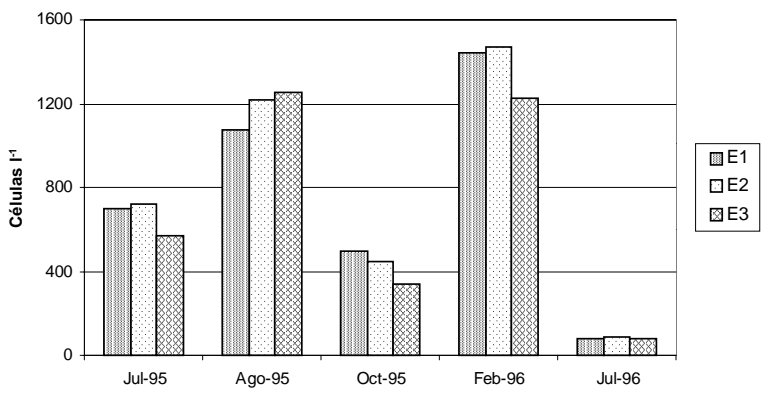

Figura 2

Densidades totales del fitoplancton de la ensenada de Utría en cada muestreo (E=Estación)

Total densities of the phytoplankton of the cove of Utría in each sampling $(\mathrm{E}=$ Station $)$

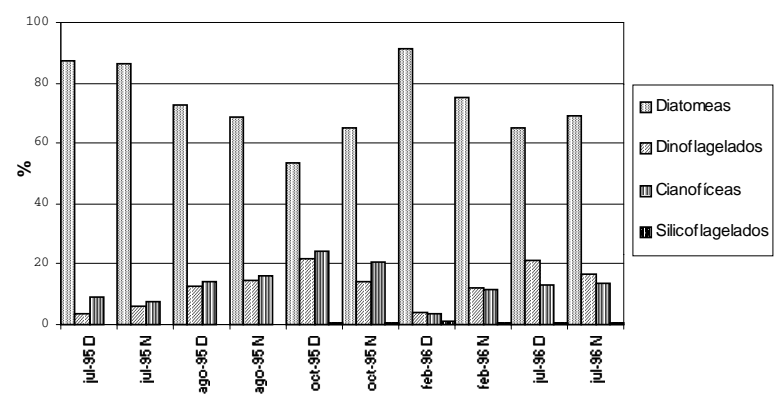

Figura 3

Porcentajes de abundancia del fitoplancton en el día y la noche en la ensenada de Utría ( $D=$ Día, $N=$ Noche)

Percentages of abundance of the phytoplankton in the day and the night in the cove of Utría ( $\mathrm{D}=$ Day, N= Night)

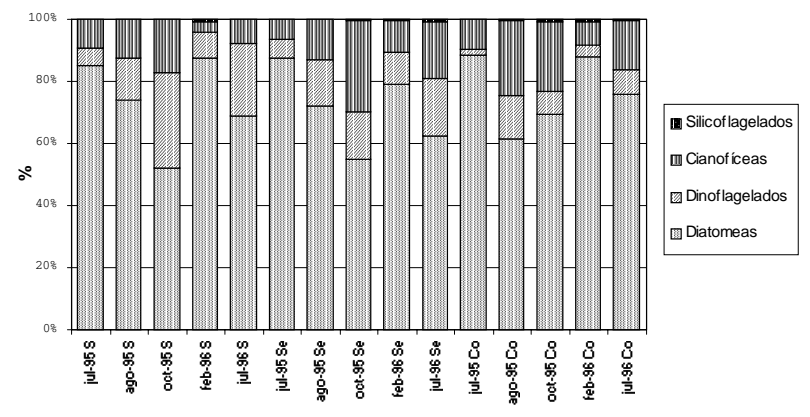

Figura 4

Porcentajes de abundancia del fitoplancton por profundidad en la ensenada de Utría ( $S=$ Superficie, $\mathrm{Se}=$ Profundidad Secchi, $\mathrm{Co}=$ Profundidad de compensación)

Percentages of abundance of the phytoplankton by depth in the cove of Utría ( $\mathrm{S}=$ Surface, $\mathrm{Se}=$ Secchi depth, $\mathrm{Co}=$ Compensation depth) perfectamente adaptadas a vivir en toda la columna de agua, la cual para la ensenada de Utría fluctúa entre 15 y $18 \mathrm{~m}$ para las estaciones internas ( 1 y 2 ) y entre 60 y 80 m para la estación 3 más alejada de la costa. Las grandes ornamentaciones, las largas proyecciones celulares y la tendencia a formar cadenas de células permiten a las diatomeas permanecer en las capas superficiales, ayudadas seguramente por la turbulencia del agua. Los dinoflagelados y las cianofíceas presentaron sus mayores porcentajes de abundancia en el muestreo de octubre de 1995 (30,4\% y 17,3\% en superficie y 15,4 y $29,5 \%$ en la profundidad Secchi, respectivamente). Según Humm \& Wicks (1988) las cianofíceas prosperan mejor en las capas superficiales que en las profundas, sin embargo, en las aguas de Utría se encontraron mejor representadas en las profundidades Secchi y de compensación, en las cuales hay buena disponibilidad de luz. Los dinoflagelados, especialmente del género Ceratium, formaron cadenas de máximo cuatro células; en algunos trabajos sobre fitoplancton del Pacífico y del Caribe (Calderón 1979, Carbonell 1982), se menciona que ciertas especies de Ceratium producen cadenas de 4 a 12 individuos en zonas profundas (mayores de $20 \mathrm{~m}$ ), donde la turbulencia es menor; la formación de cadenas cortas de Ceratium en Utría sugeriría que las condiciones físicas de la ensenada son de oleaje y turbulencia altos, pues estas características facilitarían su permanencia como células solitarias, bien representadas en la superficie. La estación 3 , sin ser oceánica, está menos expuesta a la influencia de aguas estuarinas; al ser más profunda (60 a $80 \mathrm{~m}$ ) puede tener mayor estratificación y los movimientos ascensionales se darían con menor intensidad. El influjo de las aguas oceánicas de fondo en esta estación se puede ver a través de la presencia de Planktoniella sol, diatomea propiamente oceánica (Oviedo 1989), la cual siempre ocurrió en las profundidades Secchi y de compensación, pero nunca en superficie.

Diferencias entre estaciones. En todas las estaciones y muestreos las diatomeas, específicamente las céntricas, obtuvieron la mayor representación (Fig. 5). Los meses en que la trasparencia fue menor (agosto y febrero, tabla 1 ), en especial en la estación 1, concordaron con las mayores densidades fitoplanctónicas (Fig. 2). En parte, estos menores valores de transparencia indican una mayor densidad de microalgas, las cuales reducen la penetración de la luz, pero también pueden señalar que el incremento en la abundancia fitoplanctónica puede deberse a una mayor disponibilidad de nutrientes en las aguas menos transparentes provenientes del manglar (Kjerve \& Lacerda 1993); igualmente, debe tenerse en cuenta que en el manglar existe mayor área de colonización donde se pueden desarrollar algunos grupos de diatomeas perifíticas. Al parecer, las diatomeas se encuentran mejor adaptadas a ambientes 
costeros que oceánicos (Corchuelo \& Moreno 1983, Castillo 1984). Por otra parte, se esperaría que la estación 3 presentara mayor abundancia de dinoflagelados, ya que se encuentran mejor adaptados a ambientes oceánicos. Sin embargo, en este sitio las diatomeas fueron dominantes durante todos los muestreos, lo que permite considerarlo como de aguas neríticas con alguna influencia oceánica. Los trabajos realizados en áreas alejadas de la costa en el Pacífico colombiano, la mayoría mediante cruceros oceanográficos, muestran que las especies típicamente oceánicas corresponden a los dinoflagelados Amphisolenia bidentata y Pyrophacus steinii y a la diatomea Asterolampra sp., acompañados por los tintínidos Salpingella sp. y Undella hyalina (Vizcaíno 1992, Corchuelo \& Moreno 1983). Ninguna de estas especies se registró en los muestreos efectuados en la ensenada de Utría.

Diversidad y proporcionalidad. La diversidad de Shannon, calculada para las aguas superficiales en todos los meses y estaciones, osciló entre 3,5 y 5,3 bits (11 a 39 especies con mayor probabilidad de salir en los muestreos); la proporcionalidad fluctuó entre 0,63 y 0,83 (la comunidad presenta entre el 63 y el $83 \%$ de la diversidad máxima posible) y la dominancia de Simpson tuvo estimaciones entre 0 y 0,12 ( 0 a $12 \%$ de probabilidad de extraer dos individuos de la misma especie en un muestreo) (Fig. 6). Todos estos índices revelan una comunidad fitoplanctónica muy diversa y de alta proporcionalidad, es decir con baja dominancia de especies. Mora (1993) y Sánchez (1996) encontraron diversidades entre 2,5 y 4 bits, menores a las del presente estudio, a pesar de que estos autores determinaron la diversidad beta (la correspondiente a varios hábitats, Margalef 1980), ya que sus datos provienen de arrastres superficiales circulares que toman varios parches de la comunidad fitoplanctónica en las zonas trabajadas. En el presente estudio se determinó la diversidad alfa, es decir, la de estaciones puntuales (Margalef 1980) y aún así los índices calculados fueron elevados. Según Margalef (op. cit.), el análisis de varias comunidades fitoplanctónicas de diferentes áreas oceánicas del Caribe, el Mediterráneo y el Atlántico Noroeste de África ha proporcionado una extensa serie de valores de diversidad de Shannon, los cuales fluctúan entre 2,4 y 2,6 bits. De acuerdo con lo anterior, las diversidades del fitoplancton de la ensenada de Utría son mucho mayores que la moda de las diversidades más frecuentes en el océano abierto. Parecería que la megadiversidad de la región chocoana se manifiesta también en las microalgas planctónicas, hipótesis que deberá evaluarse en el futuro. Para entender los resultados obtenidos en Utría es muy importante considerar que los muestreos con botella capturan una gran cantidad de especies que se pierden en las colectas con red. Además, la confluencia de aguas neríticas, estuarinas y oceánicas en Utría contribuye a aumentar la diversidad del fitoplancton de la ensenada. Por otra parte, los meses de agosto de 1995 y febrero de 1996 presentaron las diversidades más altas (Fig. 6), comportamiento que coincide con las abundancias fitoplanctónicas más elevadas (Fig. 2), posiblemente porque en dichos muestreos se redujo la dominancia de algunas especies de los géneros Chaetoceros, Coscinodiscus, Rhizosolenia y Ceratium y aumentó la proporcionalidad de la comunidad. El índice de Simpson mostró una baja dominancia, coherente con la alta diversidad de Shannon.
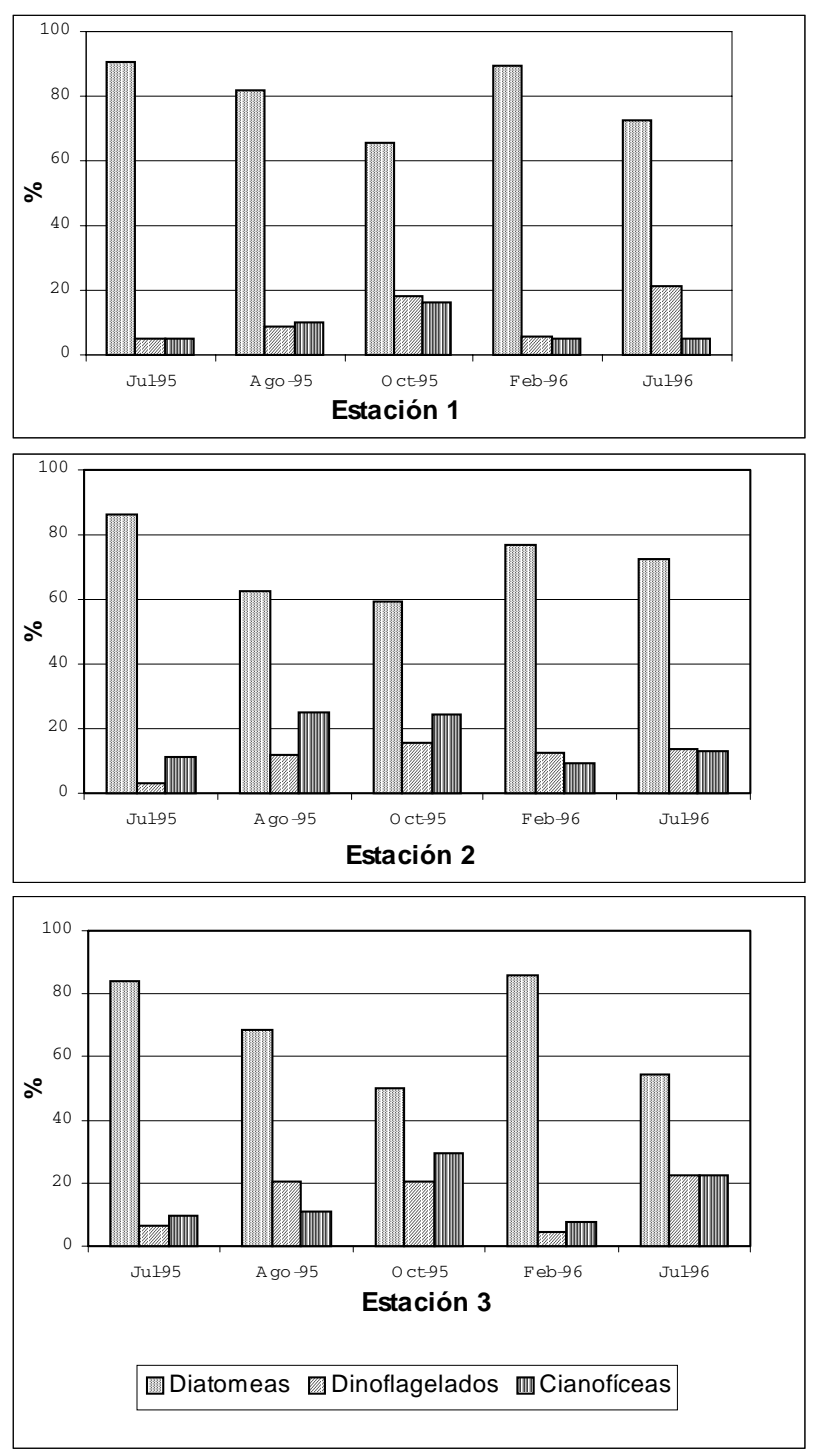

Figura 5

Porcentajes de abundancia del fitoplancton en las tres estaciones durante los cinco muestreos en la ensenada de Utría

Percentages of abundance of the phytoplankton in the three stations during the five samplings in the cove of Utría 


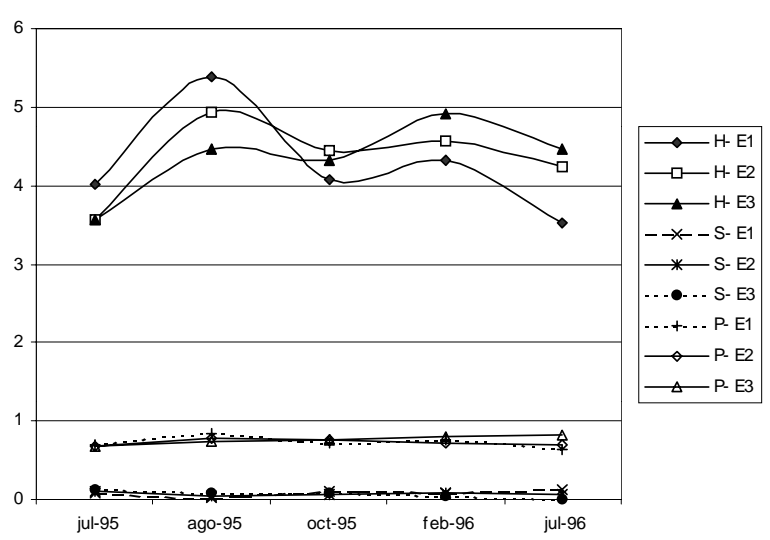

Figura 6

Diversidad de Shannon (H), dominancia de Simpson (S) e índice de proporcionalidad (P) para el fitoplancton de la ensenada de Utría

Shannon diversity (H), Simpson dominance (S) and proportionality index (P) for the phytoplankton of the cove of Utría

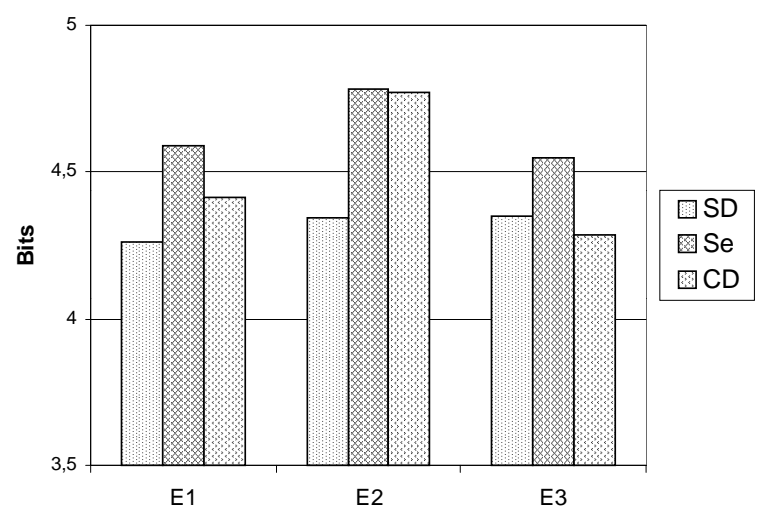

Figura 7

Diversidad promedio (Índice de Shannon) por profundidad (SD=Superficie, Se=Profundidad Secchi, CD=Profundidad de Compensación) para el fitoplancton de la ensenada de Utría (E=Estación)

Diversity average (Shannon index) by depth ( $\mathrm{SD}=$ Surface, $\mathrm{Se}=$ Secchi deep, $\mathrm{CD}=$ Compensation depth) for the phytoplankton of the cove of Utría ( $\mathrm{E}=$ Station)

La estación 2 presentó las diversidades más altas en las tres profundidades (Fig. 7). Aún cuando estas diferencias no son considerables con respecto a las estaciones 1 y 3 , podrían indicar algún tipo de influencia del coral en la zona 2, la cual no puede explicarse con los datos disponibles; por otra parte, al ser menos profunda (15 m) se pueden dar procesos de resuspensión de las microalgas, ocasionados por vientos locales y por los mismos movimientos mareales, lo que aumentaría la diversidad en esta estación.

Análisis de clasificación. La asociación de los diferentes muestreos, basada en los promedios de las abundancias fitoplanctónicas en cada estación, se muestra en la figura 8. La unión de los grupos (con una similaridad mayor al $60 \%)$ estuvo dada por las fechas de muestreo; de esta manera, los muestreos de julio de 1995 (M1), agosto de 1995 (M2) y octubre de 1995 (M3) se separaron claramente, mientras que los muestreos de febrero de 1996 (M4) y julio de 1996 (M5) se segregaron con menos precisión. Estos resultados indican que la composición de la comunidad fitoplanctónica fue diferente y característica para cada mes en que se visitó la ensenada, en especial para 1995. Dichas diferencias se dieron principalmente al nivel de especies, ya que en conjunto, los grandes grupos de microalgas conservaron una composición semejante durante el año de muestreo (Fig. 5). El análisis de varianza de las variables fisicoquímicas indicó que la salinidad ( $\mathrm{F}=9,5 \quad \mathrm{P}=0,0019)$ y el oxígeno disuelto $(\mathrm{F}=10,54 \mathrm{P}=0,0013)$ superficiales tuvieron diferencias significativas entre muestreos y que tales diferencias se debieron a los mayores valores de salinidad y menores de oxígeno en los meses de julio y agosto de 1995 (M1 y M2). Por lo tanto, es posible que estas condiciones ambientales fueran las causantes, al menos parcialmente, de los cambios en la composición del fitoplancton; no debe descartarse el papel de los nutrientes disueltos, los cuales no se evaluaron en este trabajo. De otro lado, el análisis de clasificación con base en las variables fisicoquímicas (figura 9) reveló dos aspectos interesantes del ambiente de la ensenada. Primero, los valores de similitud fueron muy altos (mayores al 90\%) para todos los grupos y segundo, la afinidad ocurrió entre estaciones y no entre fechas de muestreos. Sobre el primer punto, la elevada similitud entre todas las estaciones evidencia cierta regularidad en las características fisicoquímicas de la ensenada de Utría. En cuanto al segundo aspecto, el análisis confirma que a pesar de dicha homogeneidad, las áreas de la ensenada tienden a ser diferentes independientemente del mes de muestreo, de manera que la estación cercana a las áreas de manglar (E1), de menores transparencia y salinidad y mayor oxígeno disuelto (tabla 1), se segrega de las estaciones sobre el coral (E2) y en la entrada de la ensenada (E3), las cuales se parecen más entre sí. En resumen, se puede decir que los cambios fisicoquímicos del agua de la ensenada (a excepción de la salinidad y el oxígeno) no fueron muy significativos entre muestreos, pero que a pesar de esto la comunidad fitoplanctónica fue diferente en cada época; posiblemente el nitrógeno y el fósforo disueltos pueden provocar tales cambios en la composición y abundancia del fitoplancton, pero dicha influencia deberá evaluarse en trabajos futuros. 


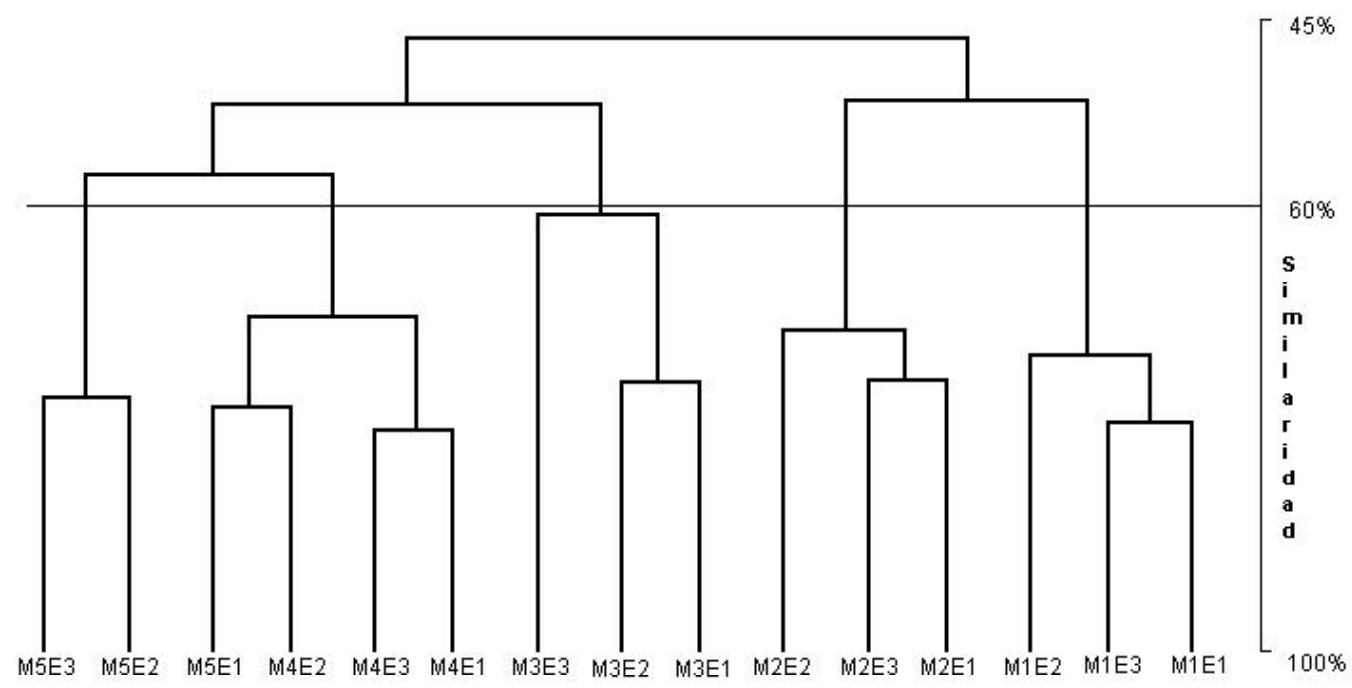

Figura 8

Dendrograma de clasificación de los muestreos de fitoplancton en la ensenada de Utría (M=muestreo, E=Estación)

Classification cluster of the phytoplankton samplings in the cove of Utría (M= Sampling, E= Station)

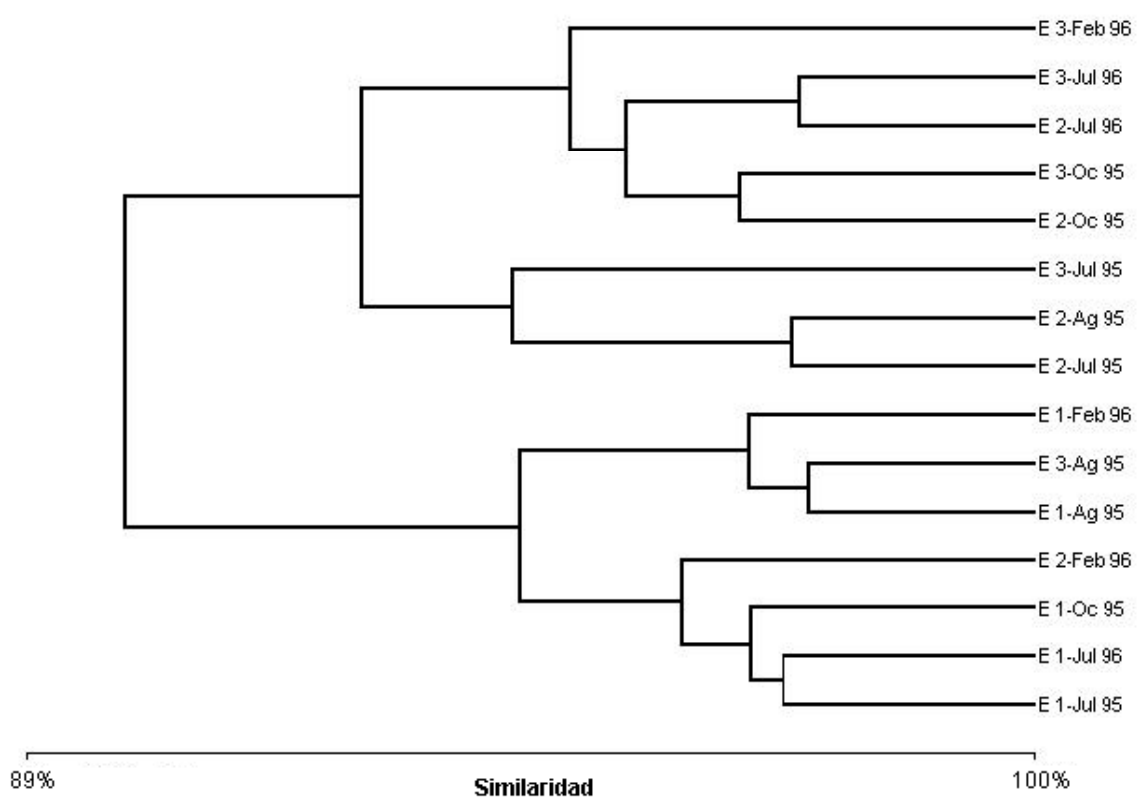

Figura 9

Dendrograma de clasificación de los muestreos fisicoquímicos en la ensenada de Utría (E=Estación)

Classification cluster of the physicochemical sampling in the cove of Utría (E= Station) 


\section{Conclusiones}

Para el periodo de muestreo considerado, la comunidad fitoplanctónica de la ensenada de Utría se caracterizó por la preponderancia de las diatomeas, la baja abundancia de organismos y la elevada diversidad de especies, condiciones propias de ambientes oligotróficos costeros. Las variaciones en la composición de la comunidad ocurrieron principalmente entre muestreos, mientras que los cambios entre estaciones y profundidades y entre el día y la noche fueron menos intensos. Las variables fisicoquímicas que tuvieron cambios significativos entre muestreos fueron la salinidad y el oxígeno disuelto superficiales y por tanto pudieron influir sobre las modificaciones en la comunidad de microalgas. La estación 1 estuvo afectada por los aportes del sistema manglárico y presentó, junto con la estación 2, características de ambientes neríticos por estar ubicadas en una zona protegida de la influencia de las aguas externas. La estación 3 mostró condiciones más afines a ambientes costeros que oceánicos, pero con influencia de aguas abiertas, especialmente en sus características fitoplanctónicas. Los análisis clasificatorios confirmaron que la comunidad fitoplanctónica de la ensenada fue diferente en cada muestreo, a pesar de que los cambios fisicoquímicos no fueron tan marcados temporalmente, lo cual demuestra que las microalgas son muy sensibles a las condiciones ambientales de la ensenada.

\section{Agradecimientos}

Esta investigación se llevó a cabo gracias a la financiación de la Fundación Natura en Bogotá y su Estación Biológica en Utría. Los autores agradecen al personal de la Fundación Natura y del Centro de Investigaciones Científicas y Estudios Ambientales de la Universidad Jorge Tadeo Lozano, al Biólogo Luis Alfonso Vidal y a todas las personas que colaboraron con la ejecución del estudio.

\section{Literatura Citada}

American Public Health Association (APHA), American Water Works Association (AWWA), Water Pollution Control Federation (WPCF). 1992. Standard Methods for the Examination of Water and Wastewater. 19 ed. Victor Graphics, Baltimore.

Antonietti V. 1988. Phytoplankton in two bays of the Peruvian littoral in April 1987. Revista Comisión Permanente del Pacífico Sur. 127-133 p.
Arboleda M. 1988. Estudio de la productividad primaria neta en un manglar de Pelliciera rhizophorae (Triana \& Planchón) en el Parque Nacional Natural Utría, Chocó Colombia. Tesis (Biólogo), 40 p. Facultad de Ciencias, Universidad del Valle, Cali.

Avaria S. 1965. Diatomeas y sílicoflagelados de la Bahía de Valparaíso. Revista de Biología Marina, Valparaíso 12 (1-3): 61-120.

Balech E. 1977. Introducción al fitoplancton marino, 211 p. Eudeba, Buenos Aires.

Barreto MI. 1992. Evaluación del efecto de península sobre la avifauna del sotobosque en la ensenada de Utría, P.N.N. Utría, Chocó-Pacífico colombiano. Tesis (Biólogo), 52 p. Facultad de Ciencias, Universidad Javeriana, Bogotá.

Calderón E. 1979. Contribución al conocimiento del fitoplancton nerítico de Tumaco y alrededores. Tesis (Biólogo Marino), 84 p. Facultad de Ciencias del Mar, Universidad Jorge Tadeo Lozano, Bogotá.

Carbonell MC. 1982. Ceratium Schrank (Dinoflagellatae, Peridiniales) de las Islas del Rosario, Caribe colombiano. Anales del Instituto de Investigaciones Marinas de Punta Betín 12: 71-91.

Castillo F. 1982. Fitoplancton del Pacífico colombiano como indicador de masas de agua. Boletín ERFEN 2: 7-12.

Castillo F. 1984. Fitoplancton del Pacífico colombiano como indicador de masas de agua (ERFEN IV). Biología Pesquera 13: 67-70.

Castillo F \& A Vidal. 1982. Fitoplancton del Pacífico colombiano como indicadores de masas de agua. Fase I, 57 p. CIOH, Cartagena.

Constain L \& L Delgado. 1985. Dinoflagelados del Pacífico colombiano como indicadores del fenómeno El Niño, Crucero Pacífico VIII ERFEN V. Nov-Dic/82. Tesis (Biólogo Marino), 44 p. Facultad de Biología Marina, Universidad Jorge Tadeo Lozano, Cartagena.

Corchuelo M \& G Moreno. 1983. Contribución al conocimiento del fitoplancton y algunos tintínidos del Pacífico colombiano. Tesis (Biólogo Marino), 186 p. Facultad de Biología Marina, Universidad Jorge Tadeo Lozano, Bogotá.

Cupp E. 1943. Marine plankton diatoms of the West Coast of North America. University of California Press, Bulletin Scripps of Institute of Oceanography 5(1): 1-238.

Davis J. 1964. Leaflet series: Plankton, 3 p. Florida Board of Conservation, St Petesburg, Florida.

Delgado F \& L Leyton. 1985. Cuantificación del fitoplancton del Pacífico colombiano mediante clorofilas y su relación con algunos parámetros oceanográficos durante noviembre y diciembre/82. Tesis (Biólogos Marinos), 49 p. Facultad de Biología Marina, Universidad Jorge Tadeo Lozano, Bogotá. 
Díaz G. 1993. Derrotero del Pacífico colombiano. Armada Nacional. DIMAR. Centro de Investigaciones Oceanográficas e Hidrográficas. Cartagena.-Colombia. Tesis (Ingeniero Geógrafo), 90 p. Facultad de Ingeniería Geográfica, Universidad Jorge Tadeo Lozano, Bogotá.

Digby $\mathbf{P} \& \mathbf{R}$ Kempton. 1987. Multivariate analysis of ecological communities, 204 p. Chapman and Hall, London.

Dodge R. 1975. The Porocentrales (Dinophyceae). II. Revision of taxonomy within the genus Prorocentrum. Bol. J. Limn. Soc. 71: 103-125.

Escobar J, F Castillo \& C Barbosa. 1993. Estudio preliminar del fitoplancton y la estructura de la comunidad coralina de la Isla Malpelo en el Pacífico colombiano durante el Crucero Henry Von Prhal. Boletín Científico del CIOH 14: 117-125.

Gualteros W, C Hernández, A Castillo \& A Fresneda. 1992. Clorofila y seston total en la laguna costera de Cocoliso Isla Grande, Parque Nacional Natural Corales del Rosario. En: Memorias VIII Seminario Nacional de Ciencias y Tecnologías del Mar: 512-521. Comisión Colombiana de Oceanografía, Santa Marta.

Humm H \& S Wicks. 1988. Introduction and guide to the marine blue green algae, 194 p. John Wiley, New York.

Kjerve B \& LD Lacerda. 1993. Manglares del Brasil. Conservación y aprovechamiento sostenible de bosques de manglar en las regiones de América Latina y África. Ecosistemas de manglares. Informes Técnicos, Proyecto ITTO/ISME. 2: 1-265.

Kofoid C \& T Skossberg. 1928. The dinoflagellata: The dinophysoidae, 766 p. Cambridge, Massachusetts.

Ludwing J.A \& JF Reynolds. 1988. Statistical ecology, a primer on methods and computing, 337 p. John Wiley, New York.

Lund JW, C Kipling \& ED Lecren. 1958. The inverted microscope method of estimating algal numbers and the satistical basis of estimations by counting. Hidrobiology 11: $1-10$.

Margalef R. 1980. La Biosfera. Entre la termodinámica y el juego, 236 p. Omega, Barcelona.

Margalef R. 1981. Ecología, 1010 p. Omega, Barcelona.

Montagut C \& M Castillo. 1989. Distribución de los dinoflagelados durante los monitoreos del programa "ERFEN" en el Pacífico colombiano. Crucero Pacífico XI ERFEN VIII (Nov/87). Crucero Pacífico XII ERFEN IX (marzo/88). Tesis (Biólogo Marino), 186 p. Facultad de Biología Marina, Universidad Jorge Tadeo Lozano, Cartagena.

Mora ME. 1993. Contribución al conocimiento de los dinoflagelados de las zonas de surgencia oceánica y costera, durante condiciones anómalas de temperatura en el Pacífico colombiano (marzo-abril, 1992). Tesis (Biólogo Marino), 41 p. Facultad de Biología Marina, Universidad Jorge Tadeo Lozano, Cartagena.
Mosquera A. 1992. La contaminación orgánica, un posible precursor de la eutroficación en aguas de la ensenada del Tumaco. En: Memorias VIII Seminario Nacional de Ciencias y Tecnologías del Mar: 1067-1083. Comisión Colombiana de Oceanografía, Santa Marta.

Odum EP. 1986. Fundamentos de ecología, 422 p. Interamericana, México.

Oviedo D. 1989. Distribución y abundancia de las diatomeas del Pacífico colombiano durante los cruceros Pacifico XIXII ERFEN VIII y IX. Tesis (Biólogo), 145 p. Facultad de Ciencias Básicas, Universidad Javeriana, Bogotá.

Paerl H. 1988. Growth and reproductive strategies of freshwater blue-green algae (Cyanobacteria). En: Sandgren CD (ed), Growth and reproductive strategies of freshwater phytoplankton, 261-315. Cambridge University Press, Cambridge.

Pesantes F. 1978. Dinoflagelados del golfo de Guayaquil. Instituto Oceanográfico de la Armada de Ecuador 2 (2): 198.

Pinilla G. 1995. Ecología regional de pequeños lagos artificiales en el altiplano cundiboyacense, Informe Final, 185 p. Universidad Jorge Tadeo Lozano, Colciencias, Santafé de Bogotá.

Prahl H, J Cantera \& $\mathbf{R}$ Contreras. 1990. Manglares y hombres del Pacífico colombiano, 193 p. Fondo FEN Colombia, Bogotá.

Ramírez J. 1992. Contribución al conocimiento ecológico y taxonómico del fitoplancton de algunos cuerpos de agua importantes para el sector eléctrico colombiano, 77 p. FEN, ISA, Universidad de Antioquia, Medellín.

Ramírez A. 1999. Ecología aplicada. Diseño y análisis estadístico, 325 p. Universidad Jorge Tadeo Lozano, Bogotá.

Reynolds CS. 1997. Vegetation processes in the pelagic: a model for ecosystem theory, 371 p. Ecology Institute, Germany.

Sánchez E. 1996. Caracterización espacial del fitoplancton nerítico en el Pacífico colombiano durante julio-agosto de 1994. Tesis (Biólogo), 60 p. Facultad de Ciencias, Universidad del Valle, Cali.

Santra S, U Pal \& A Choudhury. 1991. Marine phytoplankton of the mangrove, delta region of West Bengal, India. Journal of the Marine Biological Association of India. 33 (1-2): 292-307.

Saunders R. 1968. Leaflet: Phytoplankton, 10 p. Florida Board of Conservation, St Petesburg, Florida.

Sournia A. 1967. Le genre Ceratium (Péridien planktonique) dans le canal de Mozambique contribution a une révision mondiale. Vie et Milieu, 18: 375-500.

Steidinger K. 1964. Leaflet series: Plankton, 5 p. Florida Board of Conservation, St Petesburg, Florida.

Taylor FJR (ed). 1987. The Biology of Dinoflagellates, 390 p. Blacwell, Oxford. 
Vargas-Faucheaux C, E Cajiao, R Steer, P Monsalve \& R Combariza. 1969. Estudio preliminar descriptivo de algunas variables oceanográficas del Pacífico colombiano (Programa ACENTO 1965-1966), 51 p. Departamento Oceanográfico Escuela Naval Almirante Padilla, Cartagena.

Vidal LA \& MC Carbonell. 1977. Diatomeas y dinoflagelados de la Bahía de Cartagena. Tesis (Biólogo Marino), 360 p. Facultad de Ciencias del Mar, Universidad Jorge Tadeo Lozano, Bogotá.
Vieira C. 1994. Estructura y estado actual del bosque de mangle de Utría, 58 p. FES, Fundación Natura, Bogotá.

Vizcaino Z. 1992. Fitoplancton del Pacífico colombiano como indicador biológico del Fenómeno de El Niño. Tesis (Biólogo), 92 p. Facultad de Ciencias, Universidad del Valle, Cali.

Wahlquist C. 1964. Leaflet series: Phytoplankton, 4 p. Florida Board of Conservation, St. Petesburg, Florida.

Recibido en noviembre de 2001 y aceptado en abril de 2002 